\title{
Uso de antibióticos e leveduras para controle da podridão-mole em couve-chinesa
}

\author{
Marcelo RF de Mello; Elineide B da Silveira; Ivanise O Viana; Myrzânia de L Guerra; Rosa de LR \\ Mariano \\ UFRPE, Progr. de Pós-Graduação em Fitopatologia, Av. Dom Manoel de Medeiros, s/n, Dois Irmãos, 52171-900 Recife-PE; \\ marcelomello@barreiros.ifpe.edu.br; rmariano@truenet.com.br
}

\section{RESUMO}

A podridão-mole causada por Pectobacterium carotovorum subsp. carotovorum $(P c c)$ pode ocorrer em plantios de couve-chinesa (Brassica pekinensis) com até $67 \%$ de incidência. O trabalho visou avaliar a sensibilidade in vitro de $P c c$ a bactericidas, o efeito de Mycoshield $^{\circledR}$ nas dosagens de 3,0 e 1,5 $\mathrm{g} \mathrm{L}^{-1}$, e de leveduras a $10^{8}$ $\mathrm{cel} / \mathrm{mL}$ no controle da doença em casa de vegetação e em campo. As plantas foram pulverizadas com Mycoshield ${ }^{\circledR}$ (oxitetraciclina 20\%) e leveduras (Rh1 e Rh2 (Rhodotorula spp.) e Sc1 (Saccharomyces cerevisae)) sete dias após o transplante, e inoculadas por picada com o isolado $P c c 120$, sete dias e $12 \mathrm{~h}$ após o tratamento, respectivamente. Em todos os experimentos foram avaliados os componentes epidemiológicos da doença. In vitro, 40 isolados de Pcc testados apresentaram resistência ao sulfato de cobre e sensibilidade a oxitetraciclina, estreptomicina, oxitetraciclina+estreptomicina e oxitetraciclina+sulfato de cobre, todos na concentração de $0,2 \mathrm{~g} \mathrm{~L}^{-1}$. Seis isolados de $P c c$ foram mais inibidos por Mycoshield ${ }^{\circledR}$ do que por Agri-Micina $^{\circledR}$ (oxitetraciclina 1,5\% + estreptomicina 15\%) ambos a $3,0 \mathrm{~g} \mathrm{~L}^{-1}$, não sendo inibidos por Kasumin ${ }^{\circledR}$ (casugamicina 2\%) (2,0 $\left.\mathrm{mL} \mathrm{L}^{-1}\right)$. Em casa de vegetação, Mycoshield ${ }^{\circledR}\left(3,0 \mathrm{~g} \mathrm{~L}^{-1}\right)$ reduziu a severidade e o índice de doença em até 47,4 e 19\%; já a levedura Sc1 reduziu a severidade da doença e a área abaixo da curva de progresso da doença (AACPD) em até 27,6 e 39,3\%, respectivamente, enquanto Rh1 reduziu a AACPD em até 33,5\%. Em campo, Mycoshield ${ }^{\circledR}$ reduziu o índice de doença $(14,4 \%)$ a severidade $(15,5 \%)$ e a AACPD (28,9\%); enquanto que Rh1 reduziu o índice de doença $(8,8 \%)$ e Sc1 reduziu a AACPD $(15,7 \%)$. Conclui-se que o Mycoshield ${ }^{\circledR}$ e as leveduras apresentaram baixa eficiência para controle da podridãomole da couve-chinesa em campo.

Palavras-chave: Brassica pekinensis, Pectobacterium carotovorum subsp. carotovorum, Saccharomyces cerevisiae, Rhodotorula sp., oxitetraciclina, estreptomicina.

\section{ABSTRACT \\ Use of antibiotics and yeasts for controlling Chinese cabbage soft rot}

The soft rot caused by Pectobacterium carotovorum subsp. carotovorum (Pcc) may occur in Chinese cabbage (Brassica pekinensis) plantations presenting till $67 \%$ of incidence. In this research we evaluated the $P c c$ sensibility to bactericides in vitro, the effect of Mycoshield ${ }^{\mathbb{R}}$ at 3.0 and $1.5 \mathrm{~g} \mathrm{~L}^{-1}$, and yeasts at $10^{8} \mathrm{cel} / \mathrm{mL}^{-1}$ to control the disease in greenhouse and field. Plants were sprayed with Mycoshield ${ }^{\circledR}$ (oxitetracycline 20\%) and yeasts (Rh1 and Rh2 (Rhodotorula spp.) and Sc1 (Saccharomyces cerevisae)) seven days after transplant and inoculated with the isolate Pcc120 seven days and $12 \mathrm{~h}$ after treatment, respectively. In all experiments disease epidemiological components were evaluated. In vitro 40 Pcc isolates were resistant to copper sulfate and sensitive to oxitetracycline, streptomycin, oxitetracycline + streptomycin and oxitetracycline + copper sulfate all at $0.2 \mathrm{~g} \mathrm{~L}^{-1}$. Six Pcc isolates were more inhibited by Mycoshield ${ }^{\circledR}$ than by Agri-Micina ${ }^{\circledR}$ (oxitetracycline $1.5 \%+$ streptomycin $15 \%$ ) both at $3.0 \mathrm{~g} \mathrm{~L}^{-1}$, but there was no inhibition by Kasumin ${ }^{\circledR}$ (Kasugamicin 2\%) $\left(2.0 \mathrm{~mL} \mathrm{~L}^{-1}\right)$. In greenhouse Mycoshield ${ }^{\circledast}$ at $3.0 \mathrm{~g} \mathrm{~L}^{-1}$ reduced disease severity and disease index up to 47.4 and $19.0 \%$. The yeast $\mathrm{Sc} 1$ reduced disease severity and area under the disease progress curve (AUDPC) up to 27.6 and $39.3 \%$ respectively, while Rh1 reduced AUDPC up to $33.5 \%$. In field Mycoshield ${ }^{\circledR}$ reduced the disease index (14.4\%) severity $(15.5 \%)$ and AUDPC (28.9\%), while Rh1 reduced disease index by $8.8 \%$ and $\mathrm{Sc} 1$ reduced the AUDPC by $15.7 \%$. In conclusion Mycoshield ${ }^{\circledR}$ and yeasts showed low efficiency for controlling soft-rot of Chinese cabbage in field.

Keywords: Brassica pekinensis, Pectobacterium carotovorum subsp. carotovorum, Saccharomyces cerevisiae, Rhodotorula sp., oxitetracycline, streptomycin.

\section{(Recebido para publicação em 24 de novembro de 2009; aceito em 28 de fevereiro de 2011) (Received on November 24, 2009; accepted on 28 February, 2011)}

$\mathrm{O}^{\infty}$ estado de Pernambuco é um dos principais produtores de crucíferas no Nordeste brasileiro, sendo os municípios de Camocim de São Felix e Chã Grande os maiores produtores de couvechinesa (Brassica pekinnensis L.). Para essa cultura, a podridão-mole causada por Pectobacterium carotovorum subsp. carotovorum (Pcc) (Jones) Hauben et al. se destaca como uma importante doença (Kikumoto, 2000), tendo sido em 2004 assinalada em 22 áreas de cultivo amostradas na mesoregião Agreste de Pernambuco, com incidência variando de 1 a 67\% (Silva et al., 2005).

O controle da podridão-mole é muito difícil, uma vez que $P c c$ sobrevive na água, no solo, em restos culturais infec- tados, na rizosfera de plantas cultivadas ou invasoras e epifíticamente na filosfera de plantas hospedeiras ou invasoras (Kikumoto, 1980; Pérombelon \& Kelman, 1980). Estudos têm sido realizados com variedades resistentes (Ren et al., 2001a, 2001b), plantas transgênicas (Fray et al., 1999; Mãe et al., 2001), controle biológico (Barra et al., 2009; Carrer 
Filho et al., 2009; Cladera-Olivera et al., 2006; Dong et al., 2004; Manefield et al., 2001), uso de cálcio (Flego et al., 1997), indutores de resistência (Benelli et al., 2004) e emprego de antibióticos ou fungicidas cúpricos (Zambolim et al., 1997). No entanto, a maioria destas pesquisas foi realizada em laboratório e/ou envolvendo outros hospedeiros que não a couve-chinesa. Com relação a este patossistema específico, no Brasil ainda não existem cultivares resistentes, restando a utilização dos agrotóxicos.

Na utilização de antibióticos para controle de bacterioses deve-se considerar o custo, registro para a cultura, período de carência e, principalmente, a interferência no ecossistema envolvido. O reduzido número de agroquímicos registrados para doenças bacterianas em hortaliças favorece a utilização de produtos indevidos e ineficazes. Existem registros de quatro formulados comerciais contendo antibióticos de uso agrícola, a Agri-Micina ${ }^{\circledR}$ (oxitetraciclina $1,5 \%$ + estreptomicina 15\%); o Agrimai$\operatorname{cin}^{\circledR} 500$ (oxitetraciclina 3\% + sulfato de cobre 40\%); o Kasumin ${ }^{\circledR}$ (casugamicina 2,0\%); e o Mycoshield ${ }^{\circledR}$ (oxitetraciclina $2,0 \%$ ). Não existem produtos registrados para podridão-mole ou qualquer outra doença em couve-chinesa, desde que é considerada "minor crop". O Kasumim $^{\circledR}$ é registrado para podridãomole em cenoura e o Mycoshield ${ }^{\circledR}$ para canela-preta e podridão-mole em batata e cenoura, respectivamente (Lopes; Quezado-Soares, 1997).

O controle biológico, juntamente com outras práticas de controle, constitui uma alternativa potencial dentro de um programa de manejo de doenças de plantas. Dentre diversos agentes de biocontrole, de acordo com ValdebenitoSanhueza (2000), as leveduras são promissoras e têm sido utilizadas com eficiência, pois são integrantes da microbiota epifítica, endofítica e do solo onde se desenvolvem as plantas, competem por nutrientes, colonizam ferimentos e podem induzir resistência. As principais leveduras biocontroladoras são Aureobasidium spp., Cryptococcus spp., Rhodotorula spp., Saccharomyces spp. e Sporobolomyces spp. (ValdebenitoSanhueza, 2000).

Considerando as perdas causadas pela podridão-mole à produção de couve-chinesa em Pernambuco, a ineficácia das medidas de controle atualmente utilizadas e a carência de pesquisas com antibióticos e biocontroladores na interação Pcc x couve-chinesa, este trabalho teve por objetivo avaliar o efeito de antibióticos e leveduras no controle dessa doença.

\section{MATERIAL E MÉTODOS}

Obtenção de isolados e preparo de suspensões - Os 40 isolados de Pcc foram obtidos da Coleção de Culturas do Laboratório de Fitobacteriologia da Universidade Federal Rural de Pernambuco (UFRPE), provenientes de plantas de couve-chinesa (19 isolados) e alface (21 isolados) com infecção natural, coletadas nos municípios de Camocim de São Félix, Chã Grande e Vitória de Santo Antão. Os dez isolados de leveduras foram selecionados entre gêneros frequentemente utilizados no biocontrole de doenças de plantas. Foram obtidos da coleção de culturas do Laboratório de Fitobacteriologia da UFRPE [Rhodotorula sp. 4IIIA (Rh1) e Rhodotorula sp. 4IIIB (Rh2); Saccharomyces cerevisae Hansen (Sc1) e Saccharomyces sp. (Sc sp.)] e da Micoteca do Departamento de Micologia da Universidade Federal de Pernambuco [S. cerevisae (2658 e 5107); Pichia membranaefaciens Hansen (2611); Aureobasidium pullulans (De Bary) Arnaud (2571 e 2837) e Rhodotorula minuta (Saito) Harrison (5368)]. As suspensões bacterianas e de leveduras foram preparadas a partir de cultivo em NYDA (20 ágar, 10 glicose, 5 extrato de levedura, 3 extrato de carne, 5 peptona bacteriológica $\mathrm{g} \mathrm{L}^{-1}$ de água destilada) a $28 \pm 2^{\circ} \mathrm{C}$ durante $36-48$ h e as concentrações foram ajustadas, respectivamente em fotocolorímetro para $1 \mathrm{x}$ $10^{9}$ ufc $\mathrm{mL}^{-1}$ e em câmara de Neubauer para $10^{8} \mathrm{cel} \mathrm{mL}^{-1}$.

Sensibilidade in vitro de Pcc a bactericidas - Alíquotas de $5 \mu \mathrm{L}$ das suspensões de 40 isolados de $P c c$ foram depositadas em triplicata sobre meio NYDA suplementado com oxitetraciclina, estreptomicina e sulfato de cobre e misturas de oxitetraciclina + estreptomicina; oxitetraciclina + sulfato de cobre e estreptomicina + sulfato de cobre, sendo utilizado $0,2 \mathrm{~g} \mathrm{~L}^{-1}$ de cada antibiótico isoladamente ou em mistura. As placas foram mantidas em incubadora B.O.D. a $28 \pm 2^{\circ} \mathrm{C}$ durante 48 horas e a avaliação foi realizada considerando-se como resistentes os isolados que apresentaram crescimento confluente nas três repetições.

Seis isolados de Pcc selecionados com base na reação aos bactericidas, ao hospedeiro e município de origem foram testados para sensibilidade a Agri-Micina $^{\circledR}$ (Pfizer $^{\circledR}$, oxitetraciclina, $1,5 \%$; sulfato de estreptomicina, $15 \%$ ), Kasumin $^{\circledR}$ (Arysta Lifescience ${ }^{\circledR}$, casugamicina 2,0\%) e Mycoshield ${ }^{\circledR}\left(\right.$ Pfizer $^{\circledR}$, oxitetraciclina, 20\%), utilizando dosagens recomendadas para hortaliças, respectivamente $3,0 \mathrm{~g}, 2,0 \mathrm{~mL}$ e $3,0 \mathrm{~g}$ de produto comercial $\mathrm{L}^{-1}$ de água. Alíquotas de $3 \mathrm{~mL}$ das suspensões bacterianas concentradas foram adicionadas a $100 \mathrm{~mL}$ de NYDA fundente, homogeneizando-se e vertendo-se em placas de Petri. Após a solidificação do meio, discos de papel de filtro contendo os antibióticos nas dosagens citadas foram colocados em quatro pontos eqüidistantes. As testemunhas foram constituídas por discos contendo apenas água destilada esterilizada. As placas foram mantidas em B.O.D. a $28 \pm 2^{\circ} \mathrm{C}$ durante $24 \mathrm{~h}$ e a avaliação realizada pela medição do halo de inibição do crescimento bacteriano.

O primeiro experimento foi qualitativo, com delineamento inteiramente casualizado e três repetições, sendo a unidade experimental uma placa com três pontos de deposição. No segundo experimento, o delineamento foi inteiramente casualizado em arranjo fatorial $3 \times 6$ (três antibióticos x 6 isolados de $P(c)$, com quatro repetições, sendo a unidade experimental uma placa com quatro discos do antibiótico.

Efeito de Mycoshield ${ }^{\circledR}$ no controle da podridão-mole da couve-chinesa em casa de vegetação - Em julho de 2008, plântulas de couve-chinesa AF-75 (Sakata ${ }^{\circledR}$ Seed Sudamerica Ltda.) com 20 dias foram transplantadas para vasos contendo $3 \mathrm{~L}$ da mistura solo:substrato (1:3). Sete dias após o transplante, o Mycoshield $^{\circledR}$, previamente selecionado in vitro, foi aplicado nas dosagens 3,0 e 1,5 $\mathrm{g} \mathrm{L}^{-1}$, pulverizando-se as plantas até o escorrimento. Sete dias após aplica- 
ção do Mycoshield ${ }^{\circledR}$, as plantas foram inoculadas pelo método de picada (com palito de dente esterilizado) na base do pecíolo da segunda folha definitiva. Este período foi selecionado considerando-se que o Mycoshield ${ }^{\circledR}$ tem ação sistêmica e que no campo a doença inicia-se nesta fase (em torno de 40 dias após o transplante); com o patógeno penetrando por ferimentos nas folhas que estão em contato com o solo infestado. No ferimento, com auxílio de micropipetador foram depositados $5 \mu \mathrm{L}$ da suspensão de Pcc120. A testemunha foi tratada com água destilada e inoculada com Pcc120. Após a inoculação, as plantas foram submetidas à câmara úmida por 6 h. Durante o período dos experimentos, a temperatura em casa de vegetação variou de 25 a $35^{\circ} \mathrm{C}$.

As avaliações foram realizadas inicialmente a cada hora durante as primeiras seis horas após a inoculação e, posteriormente, a intervalos de seis horas até $48 \mathrm{~h}$, considerando-se os seguintes componentes epidemiológicos: (a) período de incubação (PI), determinado pelo número de horas entre a inoculação e o surgimento dos sintomas da doença; (b) severidade da doença ( $\mathrm{SEV}$ ), às 48 $\mathrm{h}$ após a inoculação, estimada com o auxílio de escala descritiva de 1 a 9 (Ren et al., 2001a); (c) área abaixo da curva de progresso da doença (AACPD), calculada conforme Shaner \& Finney (1977) com base em oito avaliações; (d) índice de doença (IDO), calculado pela fórmula IDO $=\Sigma$ (grau da escala $\mathrm{x}$ frequência $) \times 100 /\left(n^{\circ}\right.$ total de unidades $\mathrm{x}$ grau máximo da escala).

O delineamento foi inteiramente casualizado, com três tratamentos (Mycoshield $^{\circledR}$ em duas dosagens + testemunha), cada tratamento com quatro repetições, sendo a unidade experimental constituída por cinco plantas.

Efeito de leveduras no controle da podridão-mole em couve-chinesa - Foram realizados dois experimentos em setembro de 2008. O primeiro, em nervuras de folhas destacadas da cultivar AF-75 com os 10 isolados de leveduras seguiu a metodologia de Guerra et al. (2008). As folhas foram lavadas com água e sabão, removendo-se o limbo foliar, ficando apenas a nervura principal. As nervuras foram desinfestadas com hipoclorito de sódio (1:3, v:v), lavadas com água destilada duas vezes, acomodadas em bandejas plásticas e perfuradas com percevejos latonados em cinco locais, distantes entre eles de $2,5 \mathrm{~cm}$. As leveduras foram aplicadas por deposição de $5 \mu \mathrm{L}$ de suspensão no ferimento e após 12 horas, foram colocados $5 \mu \mathrm{L}$ de suspensão de $P c c 120$ sobre as perfurações e foram mantidas em câmara úmida em condições de laboratório. As avaliações constaram da medição do comprimento $(\mathrm{mm})$ da lesão produzida pela bactéria nos pontos de inoculação, sendo realizadas a cada hora nas primeiras 6 horas e com intervalos de 6 horas até 48 horas após a inoculação. Foram observados PI e SEV. O experimento teve delineamento inteiramente casualizado com onze tratamentos (10 leveduras + testemunha) e cinco repetições, sendo a unidade experimental uma nervura com cinco pontos de inoculação.

No segundo experimento, de antibiose in vitro contra Pcc120, foram utilizadas três leveduras selecionadas no primeiro e a metodologia já descrita no teste de sensibilidade aos antibióticos. O delineamento experimental foi inteiramente casualizado, com quatro tratamentos (três leveduras + testemunha) e quatro repetições, sendo a unidade experimental uma placa com quatro pontos de deposição.

Um terceiro experimento foi realizado em casa de vegetação com as três leveduras, utilizando metodologia similar ao que testou o Mycoshield ${ }^{\circledR}$. Durante o período dos experimentos, a temperatura em casa de vegetação variou de 25 a $35^{\circ} \mathrm{C}$. O delineamento experimental foi inteiramente casualizado, composto por quatro tratamentos (três leveduras + testemunha), com quatro repetições sendo a unidade experimental constituída por cinco plantas.

Efeito de Mycoshield ${ }^{\circledR}$ e leveduras no controle da podridão-mole em campo - Em campo comercial de couvechinesa (janeiro de 2009) foram testados o Mycoshield ${ }^{\circledR}$ na dosagem mais eficiente $\left(3,0 \mathrm{~g} \mathrm{~L}^{-1}\right)$ e as leveduras Sc1 e Rh1, previamente selecionados em casa de vegetação. A metodologia utilizada para aplicação do antibiótico, da levedura e para inoculação de Pcc120 foi seme- lhante à descrita nos experimentos de casa de vegetação. As mudas preparadas em bandejas foram transplantadas aos 20 dias para solo natural de textura areno-argilosa, com espaçamento de $70 \mathrm{x}$ $30 \mathrm{~cm}$ e irrigadas diariamente por gotejamento. O delineamento experimental foi em blocos inteiramente casualizados, composto por quatro blocos, cada um com quatro tratamentos (Mycoshield ${ }^{\circledR}$, duas leveduras e testemunha), sendo a unidade experimental constituída por 10 plantas.

Análises estatísticas - Todos os experimentos foram repetidos, com exceção daquele executado em campo. No primeiro experimento foi realizado o teste de correlação de Pierson entre hospedeiro, município e reação a sulfato de cobre + estreptomicina. Os dados dos outros experimentos foram submetidos à análise de variância e as médias comparadas pelo teste de Duncan $(\mathrm{p} \leq 0,05)$. As análises estatísticas foram realizadas com o auxílio do programa $\mathrm{SAEG}^{\circledR}$ 9.0 (Universidade Federal de Viçosa, 2005).

\section{RESULTADOS E DISCUSSÃO}

Os 40 isolados de Pcc apresentaram sensibilidade in vitro aos bactericidas oxitetraciclina e estreptomicina e resistência ao sulfato de cobre na concentração de $0,2 \mathrm{~g} \mathrm{~L}^{-1}$. Todos os isolados foram sensíveis às misturas oxitetraciclina + sulfato de cobre e oxitetraciclina + estreptomicina, e $62,5 \%$ dos isolados foram resistentes à mistura sulfato de cobre + estreptomicina. Neste último caso, as diferenças entre os isolados quanto à resistência a mesma mistura, sugerem que não houve interação entre os produtos, mas apenas diversidade genética entre os isolados. Não houve correlação entre hospedeiro, município e reação a sulfato de cobre + estreptomicina (teste de Pierson, $\mathrm{p} \leq 0,05$ ).

Para o teste com produtos comerciais foram selecionados os isolados Pcc46, Pcc78, Pcc84, Pcc112, Pcc118 e $P c c 120$, representativos de couvechinesa, alface e dos municípios $\mathrm{Ca}$ mocim de São Félix, Chã Grande e Vitória de Santo Antão, todos sensíveis a oxitetraciclina, estreptomicina, oxite- 
Tabela 1. Efeito de oxitetraciclina (Mycoshield ${ }^{\circledR}$, Pfizer ${ }^{\circledR}$ - oxitetraciclina 20\%) no controle da podridão-mole em couve-chinesa, avaliado por período de incubação (PI), índice de doença (IDO), severidade (SEV) e área abaixo da curva de progresso da doença (AACPD) em casa de vegetação (effect of oxitetracycline (Mycoshield ${ }^{\circledR}$, Pfizer $^{\circledR}$ (oxitetracycline $20 \%$ ) on the control of soft rot of Chinese cabbage evaluated by incubation period (PI), disease index (IDO), severity (SEV) and area under the disease progress curve (AACPD) under greenhouse conditions). Recife, UFRPE, 2008.

\begin{tabular}{|c|c|c|c|c|c|c|c|c|}
\hline \multirow{2}{*}{ Tratamento } & \multicolumn{4}{|c|}{$1^{\circ}$ experimento } & \multicolumn{4}{|c|}{$2^{\circ}$ experimento } \\
\hline & PI (h) & IDO & SEV & AACPD & PI (h) & IDO & SEV & AACPD \\
\hline Mycoshield $^{\circledR}\left(3,0 \mathrm{~g} \mathrm{~L}^{-1}\right)$ & $19,0 \mathrm{a}$ & $15,0 \mathrm{~b}$ & $3,4 \mathrm{~b}$ & $7,5 \mathrm{a}$ & $20,5 \mathrm{a}$ & $3,9 \mathrm{~b}$ & $3,1 \mathrm{~b}$ & $4,9 \mathrm{~b}$ \\
\hline $\operatorname{Mycoshield}^{\circledR}\left(1,5 \mathrm{~g} \mathrm{~L}^{-1}\right)$ & $18,5 \mathrm{a}$ & $17,9 \mathrm{a}$ & $5,4 \mathrm{a}$ & $7,0 \mathrm{a}$ & $20,0 \mathrm{a}$ & $4,5 \mathrm{a}$ & $6,2 \mathrm{a}$ & $9,6 \mathrm{a}$ \\
\hline Testemunha & $18,0 \mathrm{a}$ & $18,5 \mathrm{a}$ & $5,7 \mathrm{a}$ & $8,0 \mathrm{a}$ & $19,5 \mathrm{a}$ & $4,4 \mathrm{a}$ & $5,9 \mathrm{a}$ & $11,0 \mathrm{a}$ \\
\hline $\mathrm{CV}(\%)$ & 14,0 & 10,5 & 13,8 & 9,5 & 9,5 & 6,4 & 11,6 & 22,3 \\
\hline
\end{tabular}

Média de quatro repetições; médias seguidas de mesma letra nas colunas não diferem estatisticamente entre si, Teste de Duncan, $\mathrm{p} \leq 0,05$ (means of four replications; means followed by the same letter in the column did not differ significantly from each other, Duncan test, $\mathrm{p} \leq 0.05$ ).

Tabela 2. Efeito de leveduras no controle da podridão-mole em couve-chinesa, avaliado por período de incubação (PI), índice de doença (IDO), severidade (SEV) e área abaixo da curva de progresso da doença (AACPD) em casa de vegetação (effect of yeasts on the control of soft rot of Chinese cabbage evaluated by incubation period (PI), disease index (IDO), severity (SEV) and area under the disease progress curve (AACPD) under greenhouse conditions). Recife, UFRPE, 2008.

\begin{tabular}{|c|c|c|c|c|c|c|c|c|}
\hline \multirow{2}{*}{ Tratamento } & \multicolumn{4}{|c|}{$1^{\circ}$ experimento } & \multicolumn{4}{|c|}{$2^{\circ}$ experimento } \\
\hline & PI (h) & IDO & SEV & AACPD & PI (h) & IDO & SEV & AACPD \\
\hline Rh1, Rhodotorula sp. & $21,2 \mathrm{a}$ & $50,3 \mathrm{ab}$ & $4,3 \mathrm{ab}$ & $11,5 \mathrm{bc}$ & $20,0 \mathrm{a}$ & $51,0 \mathrm{a}$ & $4,3 \mathrm{ab}$ & $12,5 \mathrm{~b}$ \\
\hline $\mathrm{Rh} 2$, Rhodotorula sp. & $16,9 \mathrm{~b}$ & $54,4 \mathrm{a}$ & $3,9 \mathrm{bc}$ & $14,6 a b$ & $19,5 \mathrm{a}$ & $49,5 b$ & $3,7 \mathrm{bc}$ & $14,6 \mathrm{ab}$ \\
\hline Sc1, Saccharomyces & $21,0 \mathrm{a}$ & $46,6 \mathrm{~b}$ & $3,4 \mathrm{c}$ & $9,9 \mathrm{c}$ & $21,0 \mathrm{a}$ & $52,5 \mathrm{ab}$ & $3,3 \mathrm{c}$ & $11,7 \mathrm{~b}$ \\
\hline Testemunha & $22,5 \mathrm{a}$ & $52,1 \mathrm{ab}$ & $4,7 \mathrm{a}$ & $16,3 \mathrm{a}$ & $21,5 \mathrm{a}$ & $55,0 \mathrm{ab}$ & $4,5 \mathrm{a}$ & $18,8 \mathrm{a}$ \\
\hline CV (\%) & 7,8 & 6,8 & 8,3 & 8,1 & 10,0 & 8,5 & 10,9 & 8,4 \\
\hline
\end{tabular}

Média de quatro repetições; médias seguidas de mesma letra nas colunas não diferem estatisticamente entre si, Teste de Duncan, $\mathrm{p} \leq 0,05$ (means of four replications; means followed by the same letter in the column did not differ significantly from each other, Duncan test, $\mathrm{p} \leq 0.05$ ).

Tabela 3. Efeito de oxitetraciclina (Mycoshield ${ }^{\circledR}$, Pfizer $^{\circledR}$, oxitetraciclina 20\%) e leveduras no controle da podridão-mole em couve-chinesa, avaliado por período de incubação (PI), índice de doença (IDO), severidade (SEV) e área abaixo da curva de progresso da doença (AACPD) em campo comercial (effect of oxitetracycline (Mycoshield ${ }^{\circledR}$, Pfizer $^{\circledR}$, oxitetracycline 20\%) and yeasts on the control of soft rot of Chinese cabbage evaluated by incubation period (PI), disease index (IDO), severity (SEV) and area under the disease progress curve (AACPD) under field conditions). Recife, UFRPE, 2008.

\begin{tabular}{lllll}
\hline Tratamento & PI (h) & IDO & SEV & AACPD \\
\hline Mycoshield $^{\circledR}\left(3,0\right.$ g L $\left.^{-1}\right)$ & $19,4 \mathrm{c}$ & $39,8 \mathrm{~b}$ & $3,8 \mathrm{~b}$ & $5,9 \mathrm{c}$ \\
Sc1 - Saccharomyces cerevisae & $19,8 \mathrm{bc}$ & $43,2 \mathrm{ab}$ & $4,1 \mathrm{ab}$ & $7,0 \mathrm{~b}$ \\
Rh1 - Rhodotorula sp. & $21,2 \mathrm{a}$ & $42,4 \mathrm{~b}$ & $4,3 \mathrm{ab}$ & $8,0 \mathrm{a}$ \\
Testemunha & $20,8 \mathrm{ab}$ & $46,5 \mathrm{a}$ & $4,5 \mathrm{a}$ & $8,3 \mathrm{a}$ \\
\hline CV $(\%)$ & 4,0 & 5,5 & 7,4 & 8,6
\end{tabular}

Média de quatro repetições; médias seguidas de mesma letra nas colunas não diferem estatisticamente entre si, Teste de Duncan, $\mathrm{p} \leq 0,05$ (means of four replications; means followed by the same letter in the column did not differ significantly from each other, Duncan test, $\mathrm{p} \leq 0.05)$.

traciclina + sulfato de cobre e oxitetraciclina + estreptomicina e resistentes ao sulfato de cobre e ao sulfato de cobre + estreptomicina. Nesse teste, houve interação significativa entre antibióticos comerciais e isolados. Os seis isolados foram resistentes ao $\operatorname{Kasumin}^{\circledR}(2,0$
$\mathrm{mL} \mathrm{L}^{-1}$ ) e sensíveis a Agri-Micina ${ }^{\circledR} \mathrm{e}$ Mycoshield $^{\circledR}$, ambos a 3,0 g L $^{-1}$, com halos de inibição significativamente maiores para este último antibiótico. Mycoshield ${ }^{\circledR}$ inibiu ainda com maior intensidade o crescimento dos isolados Pcc78 (2,3cm), Pcc84 (2,2cm) e
Pcc118 (2,0 cm). Considerando esses resultados e a classificação toxicológica da Agri-Micina ${ }^{\circledR}$ (classe I: produto extremamente tóxico), o Mycoshield ${ }^{\circledR}$ (classe II: produto altamente tóxico) foi selecionado para os experimentos posteriores.

Nos municípios estudados não é comum a aplicação de Kasumin $^{\circledR}$ em cultivos de couve-chinesa ou alface, fato que justificaria a resistência à casugamicina. No entanto, sabe-se que a resistência a antibióticos é governada por mecanismos genéticos e os genes para resistência podem estar presentes, tanto no cromossomo principal como em plasmídeos. Em alguns casos, toda a população bacteriana já é naturalmente resistente a um ou vários antibióticos $\mathrm{e}$ existem vários exemplos em bacteriologia de plantas, denominando-se resistência múltipla constitutiva (Romeiro, 2005). A sensibilidade encontrada a Agri-Micina $^{\circledR}$ e Mycoshield ${ }^{\circledR}$ confirmou a reação dos quarenta isolados de $P c c$ aos princípios ativos destes produtos. 
Isto pode indicar que a sua utilização em alface e couve-chinesa nos municípios analisados ainda é incipiente; fato importante, principalmente pela falta de registro dos mesmos para estas hortaliças.

Os bactericidas mais utilizados comercialmente são os antibióticos oxitetraciclina e sulfato de estreptomicina e os cúpricos (Romeiro, 2005) entre os quais oxicloreto de cobre, sulfato de cobre, hidróxido de cobre e óxido cuproso (Leite Júnior, 2000). A resistência a produtos cúpricos em bactérias fitopatogênicas foi observada pela primeira vez em Xanthomonas spp. associadas com doenças em pimentão (Marco \& Stall, 1983) e tem sido relatada também em Pseudomonas spp. (Aguiar et al., 2000). Com relação aos antibióticos, diferenças na sensibilidade à estreptomicina foram observadas em Xanthomonas spp. causando mancha-bacteriana do tomateiro na Flórida (Stall \& Thayer, 1962), no Caribe e na América Central (Bouzar et al., 1999) enquanto que na Itália, onde o uso da estreptomicina não é permitido, nenhum isolado resistente de Xanthomonas spp. do pimentão foi detectado por Buonaurio et al. (1994).

Não existem produtos registrados para podridão-mole em couve-chinesa. Apenas Kasumim ${ }^{\circledR}$ e Mycoshield ${ }^{\circledR}$ são registrados para essa doença em cenoura e batata, respectivamente, sendo também indicados para fitobacterioses em outras culturas (Lopes \& QuezadoSoares, 1997).

Nos dois experimentos em casa de vegetação, o tratamento com Mycoshield ${ }^{\circledR}$ $1,5 \mathrm{~g} \mathrm{~L}^{-1}$ (50\% da dosagem comercial, ou seja, $300 \mathrm{mg} \mathrm{L}^{-1}$ de oxitetraciclina) não diferiu da testemunha em relação a nenhuma das variáveis analisadas, demonstrando ineficácia no controle da doença (Tabela 1). Já o Mycoshield ${ }^{\circledR}$ na dosagem comercial, apesar de não influenciar o PI em ambos os experimentos, promoveu reduções de 40,3 e 47,4\% na SEV da doença e de 19,0 e 11,4\% no IDO em relação à testemunha não tratada. Diferenças na AACPD foram observadas apenas no segundo experimento onde o tratamento Mycoshield ${ }^{\circledR}$ $3,0 \mathrm{~g} \mathrm{~L}^{-1}$ reduziu esta variável em 55,0\%. Esses resultados confirmaram aqueles obtidos nos experimentos in vitro, onde a eficácia da oxitetraciclina foi observada na inibição de $P c c$.

No experimento em nervuras destacadas, os 10 isolados de leveduras testados não influenciaram o PI. No entanto, os isolados Rh1, Rh2 (Rhodotorula sp.) e Sc1, 2658, 5107 (S. cerevisae) reduziram a SEV em até $84 \%$, sendo os isolados Rh1, Rh2 e Sc1 selecionados para o teste em casa de vegetação. In vitro as leveduras não inibiram $P c c$, indicando que não agem pelo mecanismo de antibiose, como era de se esperar.

Em casa de vegetação, de modo geral não foi observada diferença significativa entre tratamentos e testemunha para PI ou IDO nos dois experimentos (Tabela 2). No entanto, o isolado Sc1 diferiu da testemunha em ambos os experimentos reduzindo a SEV da doença em até $27,6 \%$ e a AACPD em até 39,3\%. O isolado Rh1 apenas reduziu a AACPD, nos dois experimentos, em até 33,5\%.

Em campo o Mycoshield ${ }^{\circledR}$ na dosagem $3,0 \mathrm{~g} \mathrm{~L}^{-1}$, reduziu significativamente o IDO, a SEV e a AACPD em respectivamente 14,$4 ; 15,5$ e $28,9 \%$ comparado à testemunha, mas o nível de eficiência foi considerado baixo em relação aos resultados de casa de vegetação. Os isolados de levedura também não apresentaram a eficiência desejada. Apenas diferiram da testemunha, Rh1 que reduziu o IDO em $8,8 \%$ e Sc1 que reduziu a AACPD em 15,7\% (Tabela 3 ). Isto pode ser explicado uma vez que em casa de vegetação as condições ambientais são parcialmente controladas e no campo fatores climáticos como precipitação e temperatura podem ter reduzido a eficácia do controle.

Dentre as diferentes medidas de controle da podridão-mole está o uso de antibióticos ou fungicidas cúpricos (Zambolim et al., 1997). No emprego de antibióticos, é importante entre outros fatores considerar a eficiência do produto e o surgimento de resistência, uma vez que, antibióticos podem tornarse ineficazes pelo uso continuado dos mesmos grupos químicos, com modos de ação semelhantes (Romeiro, 2005). Por se tratar de uma folhosa, a couvechinesa é consumida na maioria das vezes in natura. Portanto, a utilização do controle químico deve ser inserida dentro de um programa de manejo jun- tamente com outras medidas, levando-se em conta, sobretudo, o registro para a cultura e o período de carência do produto utilizado.

Considerando que a couve-chinesa tem ciclo curto, de 60 a 70 dias, a fase crítica de infecção ocorre próximo aos 20 dias após o transplante, ou seja, 45 dias após plantio, período em que as folhas e, principalmente, as nervuras, tocam o solo e inicia-se a formação da cabeça. Neste período, os tecidos da planta estão mais suscetíveis à ação das enzimas pectinolíticas produzidas por Pcc, embora as perdas continuem nas fases de colheita, estocagem e transporte (Ren et al., 2001a).

A baixa eficiência das leveduras em campo podem ter resultado da dificuldade de colonização do filoplano nas condições climáticas prevalentes neste habitat. Apesar de excelentes competidoras por nutrientes, o que resulta em maior velocidade de crescimento e capacidade de utilização dos substratos disponíveis (Gava, 1998), a colonização pelas leveduras depende não só da disponibilidade desses nutrientes e espaço, mas da microbiota e dos fatores ambientais existentes naquele local. Assim sendo, os isolados de leveduras testados apresentam pouco potencial para o controle da podridão-mole da couve-chinesa. Apesar de não agirem por antibiose e de terem como possíveis mecanismos de ação a competição e/ ou indução de resistência, os índices de controle estão abaixo daqueles esperados em um efetivo controle biológico, mesmo inserido em um contexto de manejo. Também Gomes et al. (2005) relataram que o controle da podridão-mole em tomate com o isolado de levedura LD-19 apresentou baixa eficiência, em torno de $20 \%$. Por outro lado, reduções de incidência de $100 \%$ da podridãomole foram obtidas experimentalmente em frutos de pimentão com os isolados P-5 de Pseudomonas sp. fluorescente e LD-19 de Rhodotorula sp. (Melo et al., 1995).

Ainda dentre as causas da baixa eficiência do controle obtido, podem ser citadas a alta agressividade do patógeno e o método de inoculação utilizado. No entanto, este método foi necessário para assegurar em campo a ocorrência da 
podridão-mole; e foi também utilizado por Ren et al. (2001a, 2001b) para estudos de resistência neste patossistema.

Considerando que a couve-chinesa é uma hortaliça folhosa de ciclo curto, a probabilidade do surgimento de resistência na população do patógeno e principalmente os baixos níveis de redução da intensidade da doença obtidos pelo Mycoshield ${ }^{\circledR}$ e leveduras em campo, conclui-se que ambos apresentaram baixa eficiência para o controle da podridão-mole da couve-chinesa nestas condições.

\section{AGRADECIMENTOS}

Os autores agradecem ao $\mathrm{CNPq}$, pela concessão de auxílio financeiro (Proc. 479.622/2004-3) e bolsas de iniciação científica (Myrzânia de L Guerra), apoio técnico (Ivanise O Viana) e produtividade em pesquisa (Elineide B da Silveira e Rosa de Lima R Mariano); e a CAPES, pela bolsa de doutorado de Marcelo Rodrigues F de Mello.

\section{REFERÊNCIAS}

AGUIAR L; KIMURA O; CASTILHO AMC; CASTILHO KSC; RIBEIRO RLD; AKIBA F; CARMO MG. F. 2000. Resistência ao cobre em isolados nacionais de Xanthomonas campestris pv. vesicatoria de pimentão e tomateiro. Agronomia 34:78-82.

BARRA VR; ROMEIRO, RS; GARCIA FAO; MOURAAB; SILVA HSA; MENDONÇA HL; HALFELD-VIEIRA BA. 2009. Antagonismo direto e biocontrole da podridão-mole-dotomateiro pelo uso de procariotas. Pesquisa Agropecuária Brasileira 44:327-330.

BENELLI AIH; DENARDIN ND; FORCELINI CA. 2004. Ação do acibenzolar-S-metil aplicado em tubérculos e plantas de batata contra canela preta, incitada por Pectobacterium carotovorum subsp. atrosepticum atípica. Fitopatologia Brasileira 29: 263-267.

BOUZAR H; JONES JB; STALL FJ; LOUWS FJ; SCHNEIDER M; RADEMAKER JLW; BRUIJN; JACKSON LE. 1999. Multiphasic analysis of Xanthomonas causing bacterial spot disease on tomato and pepper in the Caribbean and Central America: evidence for common lineages within and between countries. Phytopathology 89: 328-335.

BUONAURIO R; STRAVATO VM;
SCORTICHINI M. 1994. Characterization of Xanthomonas campestris pv. vesicatoria from Capsicum annuum L. in Italy. Plant Disease 78: 296-299.

CARRER FILHO, R; ROMEIRO, RS; AMARAL LS; GARCIA FAO. 2009. Potencialidade de um actinomiceto de rizosfera de tomateiro como agente de biocontrole de doenças. Horticultura Brasileira 27: 340-344.

CLADERA-OLIVERA, F; CARON, GR; MOTTA, AS; SOUTO, AA; BRANDELLI, A. Bacteriocin-like substance inhibits potato softrot caused by Erwinia carotovora. Canadian Journal of Microbiology 52: 533-539.

DONG YH; ZHANG XF; XU JL; ZHANG LH. 2004. Insecticidal Bacillus thuringiensis silences Erwinia carotovora virulence by a new form of microbial antagonism, signal interference. Applied and Environmental Microbiology 70: 954-960.

FLEGO D; PIRHONEN M; SAARILAHTI H; PALVA TK; TAPIO PE. 1997. Control of virulence gene expression by plant calcium in the phytopathogen Erwinia carotovora. Molecular Microbiology 25: 831-838.

FRAY RG; THROUP JP; DAYKIN M; WALLACE A; WIILLIAMS P; STEWART G SAB; GRIERSON D. 1999. Plant genetically modified to produce $N$-acylhomoserine lactones communicate with bacteria. Nature Biotechnology 17: 1017-1020.

GAVACAT. 1998. Seleção de estreptomicetos para controle biológico de Ralstonia solanacearum e Erwinia carotovora. Seropédica: UFRRJ. $114 p$ (Tese mestrado).

GOMES AMA; SILVEIRA EB; MARIANO RLR. 2005. Tratamento pós-colheita com cálcio e microrganismos para controle da podridãomole em tomate. Horticultura Brasileira 23: 108-111.

GUERRA ML; GUERRA IL; MELO AP; MARIANO RLR. 2008. Podridão-mole da alface e couve-chinesa: biocontrole. In: JORNADA DE ENSINO, PESQUISA E EXTENSÃO DA UFRPE, VIII. Resumos... Recife: UFRPE (CD Rom).

KIKUMOTO T. 1980. Ecological aspects of soft rot bacteria. Report of the Institute for Agricultural Research (Tohoku University) 31: 19-41.

KIKUMOTO T. 2000. Ecology and biocontrol of soft rot of Chinese cabbage. Journal of General Plant Pathology 66: 275-277.

LEITE JÚNIOR RP. 2000. Surviving with citrus canker in Brazil. In: CONGRESS OF THE INTERNATIONAL SOCIETY OF CITRICULTURE, $9^{\text {th }}$. Proceedings... Orlando: International Society of Citriculture. p. 890-896.

LOPES CA; QUEZADO-SOARES AM. 1997. Doenças bacterianas das hortaliças diagnose e controle. Brasília: EMBRAPACNPH. 70 p.
MÃE A; MONTESANO M; KOIV V; PALVA T. 2001. Transgenic plant producing the bacterial pheromone $N$-acyl-homoserine lactone exhibit enhanced resistance to the bacterial phytopathogen Erwinia carotovora. Molecular Plant-Microbe Interactions, 14: 1035-1042.

MANEFIELD M; WELCH M; GIVSKOV M; SALMOND GPC; KJELLEBERG S. 2001. Halogenated furanones from the red alga, Delisea pulchra, inhibit carbapenem antibiotic synthesis and exoenzyme virulence factor production in the phytopathogen Erwinia carotovora. FEMS Microbiology Letters 205: 131-138.

MARCO GM; STALL RE. 1983. Control of bacterial spot of pepper initiated by strains of Xanthomonas campestris pv. vesicatoria that differ in sensitivity to copper. Plant Disease 67: 779-781.

MELO RAG; MARIANO RLR; MICHEREFF SJ; MENEZES M; COELHO RSB. 1995. Controle biológico da podridão-mole do pimentão (Capsicum annum) causada por Erwinia carotovora subsp. carotovora. Summa Phytopathologica 21: 206-212.

PÉROMBELON MCM; KELMAN A. 1980. Ecology of the soft rot Erwinias. Annual Review of Phytopathology 18: 361-387.

REN J; PETZOLDT R; DICKSON MH. 2001a. Genetics and population improvement resistance to bacterial soft rot in Chinese cabbage. Euphytica 117: 197-207.

REN J; PETZOLDT R; DICKSON MH. 2001b. Screening and identification of resistance to bacterial soft rot in Brassica. Euphytica 118: 271-280.

ROMEIRO RS. 2005. Bactérias fitopatogênicas. Viçosa: Imprensa Universitária da UFV. $283 \mathrm{p}$.

SHANER G; FINNEY RE. 1977. The effect of nitrogen fertilization on the expression of slow-mildewing resistance in knox wheat. Phytopathology 15: 1051-1056.

SILVA AMF; MARIANO LR; MICHEREFF SJ; SILVEIRA EB; MEDEIROS FHV. 2005. Levantamento da intensidade da podridão-mole da alface e couve-chinesa em Pernambuco. Caatinga 20: 84-83.

STALL RE; THAYER PL. 1962. Streptomycin resistance of the bacterial spot pathogen and control with streptomycin. Plant Disease Reporter 46: 389-392.

VALDEBENITO-SANHUEZA RMV. 2000. Leveduras para o biocontrole de fitopatógenos. In: MELO IS; AZEVEDO JL. (eds). Controle biológico. Jaguariúna: Embrapa Meio Ambiente. p. 41-56.

ZAMBOLIM L; VALE FXR; COSTA H. 1997. Controle integrado das doenças de hortaliças. Viçosa: Imprensa Universitária de UFV. $122 \mathrm{p}$. 